\title{
Cloud Based GIS Approach for Monitoring Environmental Pollution in the Coastal Zone of Kalutara, Sri Lanka
}

\author{
M.S.P.M. Sirirwardane ${ }^{1 *}$, M.A.D. Samanmali ${ }^{2}$ and R.N.P. Rathnayake ${ }^{3}$ \\ ${ }^{1}$ GIS Solutions (Pvt) Ltd., 370, Galle Road, Colombo 3, Sri Lanka \\ ${ }^{2}$ Department of Geography, Faculty of Arts, University of Colombo, Sri Lanka \\ ${ }^{3}$ Faculty of Education, University of Colombo, Sri Lanka
}

Date Received: 31-12-2014 Date Accepted: 30-04-2015

\begin{abstract}
Geographic Information Systems (GIS) can be used as a powerful tool in many aspects of handling geospatial data. By considering the modern geospatial approaches, this research is focused on monitoring environmental pollution in the coastal zone of Kalutara area, with the objective of identification of existing natural resources. Green vegetation patches, water bodies and beech areas were detected using remote sensing techniques. A detailed GPS field survey was conducted and identified minor environmental resources with various pollution incidents. This information was used to improve the available data sets. The types of pollution incidents were categorised according to the severity level by considering the relationship to each natural resource. Maps were created and data was uploaded to the ArcGIS online cloud platform. Web services were hosted using this cloud infrastructure. Pollution incidents data layer has been given web based editing capabilities for field monitoring using GPS enabled mobiles. Field observations were conducted and locations of the pollution effects were uploaded into web maps from the field with related attributes. The hot spots were used to get better understanding and awareness of the environmental pollution. As the results, pollution incidents were identified and there was a significant effect to the minor environmental elements. The cloud infrastructure, helped to bring down the barriers of data sharing and the incident reporting mechanism became more convenient during the field observations.
\end{abstract}

Keywords: web GIS, costal pollution, geospatial approaches, cloud GIS

\section{Introduction}

Geographic Information Systems (GIS) can be recognised as a powerful tool in handling geospatial data for decision supporting activities. "Decision support systems (DSS) make use of a variety of information technologies and new technologies are playing an increasingly important role in decision support. One such field where new techniques have been developed is Geographic Information Systems (Keenan, 1997). GIS provides a framework for gathering and organising spatial data and related information so that it can be displayed and analysed (Esri Knowledge Base, 2014). With emerging development of Information Technology (IT) and science, GIS has been modernised. Web GIS, mobile GIS and cloud GIS techniques are become popular among the traditional GIS users as well

\footnotetext{
*Correspondence: supunsiriwardane@gmail.com

Tel: +94775255133

ISSN 2235-9370 Print/ISSN 2235-9362 Online ㄷ University of Sri Jayewardenepura
} 
as non-GIS communities. Web GIS becomes a cheap and easy way of disseminating geospatial data and processing tools. Many organisations are interested to distribute maps and processing tools without time and location restriction to users. The ability to get information through internet made spatial data providers to explore the internet resources for disseminating spatial information (Alesheikh et al., 2002). Cloud computing is another emerging trend in the IT world. It is defined as internet-based computing whereby information, IT resources, and software applications are provided to computers and mobile devices on-demand (Cloud Computing, 2014). This clearly indicates the sharing of IT resources off the premises of a particular client site.

However, when explaining the relationship with GIS and cloud computing, several aspects should be reviewed. Following definition is explaining the core of it. Cloud computing is rapidly emerging as a technology trend that almost every industry that provides or consumes software, hardware, and infrastructure can leverage. The technology and the architecture that cloud service and deployment models offer are key areas of research and development for geographic information system (GIS) technology (Kouyoumjian, 2010). According to these definitions the importance of the cloud techniques were highlighted with research and development perspectives.

\section{Methodology}

This research is focused on the cloud based GIS approach for monitoring environmental pollution in the coastal zone of Kalutara. The main objective of the study was to identify the pros and cons of the 'pollution incident reporting mechanism' and monitoring it using GIS technology. Here a special focus has taken to coastal environment pollution. In order to obtain the main objective of this study the existing natural resources were identified using satellite images by visual interpretation and remote sensing techniques and minor environmental resources were identified types of pollution incident by conducting a detailed GPS field survey. Further hosted GIS services were created on a cloud platform and reporting incidents from the field for monitoring activities and finally the incidents were analysed and the reporting mechanism was evaluated.

Three Grama Niladhari (GN) divisions were selected in the Kalutara District Secretariat (DS) divisions the study area. These GN divisions are bordering to the river "Kalu" at the coastal zone of Kalutara Urban area. The river Kalu is one of the four major rivers in Sri Lanka with a massive volume of water which are collected from the core rainfall of the wet zone. Tropical forest areas like Singharaja and western and south western part of the central hills are main sources for the river. It is fallen into the Indian ocean at Kalutara town and river mouth, lagoon and sand bars can be identified as special geomorphologic features which dominate in the study area.

Figure 1 indicates a relative location of the study area from an aerial view with the GN boundaries overlaid on a satellite image. There is another specialty of the area as it is highly interactive with natural and human activities. Kalido beach is one of the special sites which have huge attractions of the local people and the foreigners. Therefore, the interaction is higher than the other isolated coastal areas of the district. On the other hand the main city of Kalutara is well inside the GN division called "Kalutara South". This area includes population concentrated areas as well as the crowded locations like railway station, main bus stand and also the Kalutara Bodhiya temple complex. Therefore, a significant amount of population is moving through the area with a great level of interaction.

This environment is always has a trend to be changed due to various activities of the river. The massive volume of water is always has an effect on changing the geomorphologic creations. For few 
decades the river mouth has been shifted up and down, because of the energy and materials coming from the giant water body. With these factors, there is a huge discussion regarding the costal pollution and the protection of the natural beauty. Currently, the pollution and resource monitoring mechanism are not very clear for the entire area.

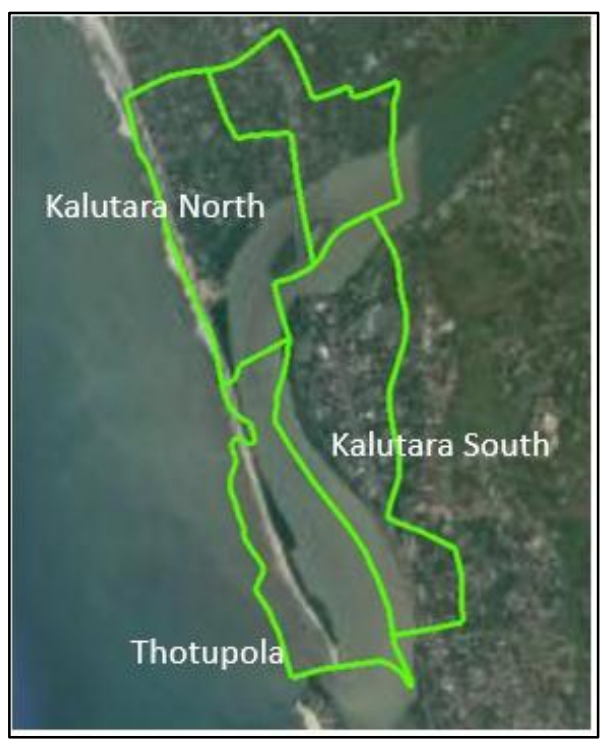

Figure1: The aerial view of the study area.

The methodology can be explained using several distinguish stages. The beginning of the process the boundaries of the study area were defined using the administrative boundaries data from the Survey Department of Sri Lanka. These boundaries were overlaid on the satellite images with proper coordinate system. The detection of available natural resources in the study area was derived through high resolution satellite images of GeoEye and web imagery services form ESRI (Environment Systems Research Institute). The row images were enhanced with several image processing techniques. Then visually interpreted with understanding of coastal geomorphology and several features were clearly identified during the process. Green vegetation patches were carefully digitized as they are smoothly distributed along the coastal zone.

Water bodies and sandy beaches were mapped using supervised image classification techniques as they were spreading unevenly within the study area. In fact, this level is not perfectly fit into the precise detection of all the resources due to the limitations of image resolutions. Therefore, a field survey was conducted using the facility of GPS (Global Positioning Systems) technology. The minor resources like sand dunes, mangrove filled river banks, seasonal salt marshes and thin stream networks were identified. At the same time the types of pollution incidents were observed.

This was done for building up a categorised data model for the pollution incidents. This data model was important for the geo-database which consisted with all the datasets available in the study area. The resources datasets were improved by the field observation results and comprehensive dataset was created. Figure 2 indicates the methodology in detail. Using the created datasets a Geodatabase was created using ArcGIS and Geodatabase domains and subtypes were assigned. Using the developed data, map documents were created with specific symbol formats. These maps were published into a cloud 
platform called ArcGIS Online and given the editing capabilities to the pollution incidents layer. The aim was to enabling the mobile based data editing from the field.

\begin{tabular}{l}
$\begin{array}{l}\text { The identification } \\
\text { of existing } \\
\text { environment and } \\
\text { available natural } \\
\text { resources }\end{array}$ \\
$\begin{array}{l}\text { Pata uploaded to } \\
\text { the ArcGIS online } \\
\text { cloud platform and } \\
\text { Mobile Application } \\
\text { for field Monitoring } \\
\text { and analyzing } \\
\text { incidents }\end{array}$ \\
\hline
\end{tabular}
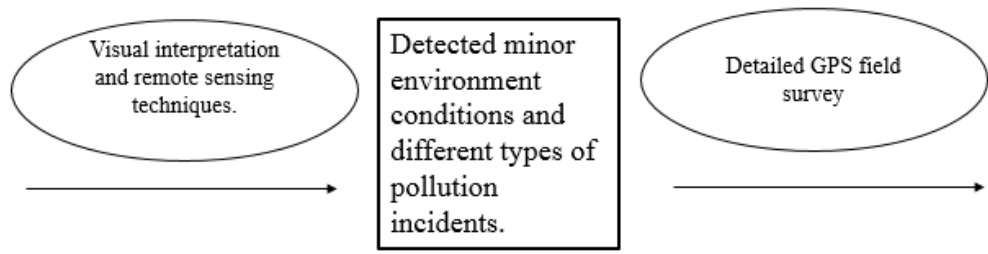

Improvement of the existing data sets available in the study area.
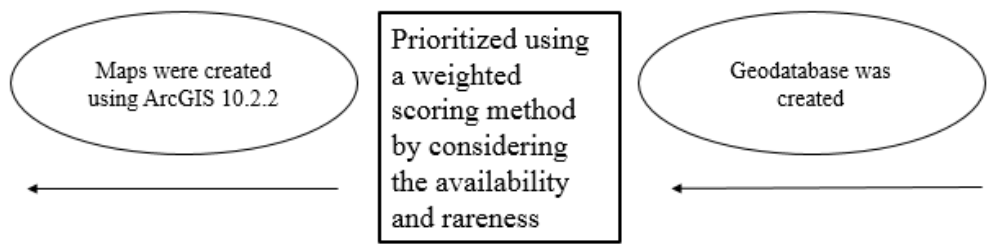

The types of pollution incidents were categorized according to the severity level.

Figure 2: The methodology used for the present study.

After uploading the data sets the pollution incident layer was hosted as a feature service which supports attachments such as photographs. Using ArcGIS online, a web map was created with the natural resources layer which mainly contained vegetation patches as well as pollution incidents. Using the web app builder in the cloud platform, a new app was created for pollution incident monitoring. This app was accessible for particular login mobile device from the mobile device. Simultaneously an operational dashboard was created to get the incidents and this operational view has the ability to display the data with all the updates from the field.

This architecture was tested from the field and incidents were uploaded to the system. The data was then processed and analysed hot spots for better understanding about the bulk of incident concentrations. Figure 3 indicates the system architecture.

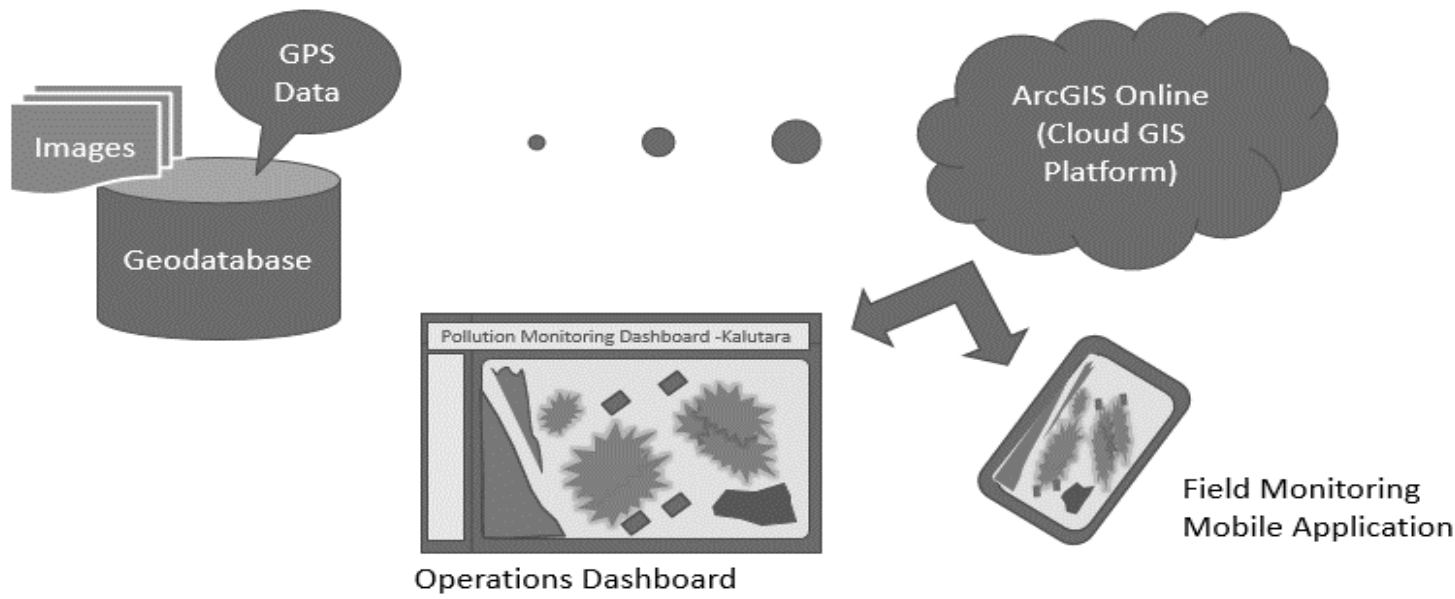

Figure 3: The system architecture with the components. 
Using the cloud infrastructure, the mobile app was able to send the information collected from the field. This was done for 3 days and 44 incidents were reported. Figure 4 indicates the appearance of the mobile app with the collected incidents. When adding a new incident as a point feature, there is an option to include attributes as well as attachments.

When the observations were taking place, a severity level was also mentioned as an attribute, this level was created during the data model creation, with the knowledge achieved at the first field visit. Some expertise knowledge as well as research experience are used for this process and there are 1-5 values which increases the severity with the higher number. During the observations, by considering the human sensors, a value was assigned with the discussion of three participants of the field visit. But there is a difference of ideas and if the members are changed the values can be also changed. That act as limitation of this severity indicator and there is no chemical testing or modelling of the phenomena to get a precise measurement of the pollution level from the field. This stage is limited to observed incidents and some sort of severity level indication of the problem using only the human sensors.

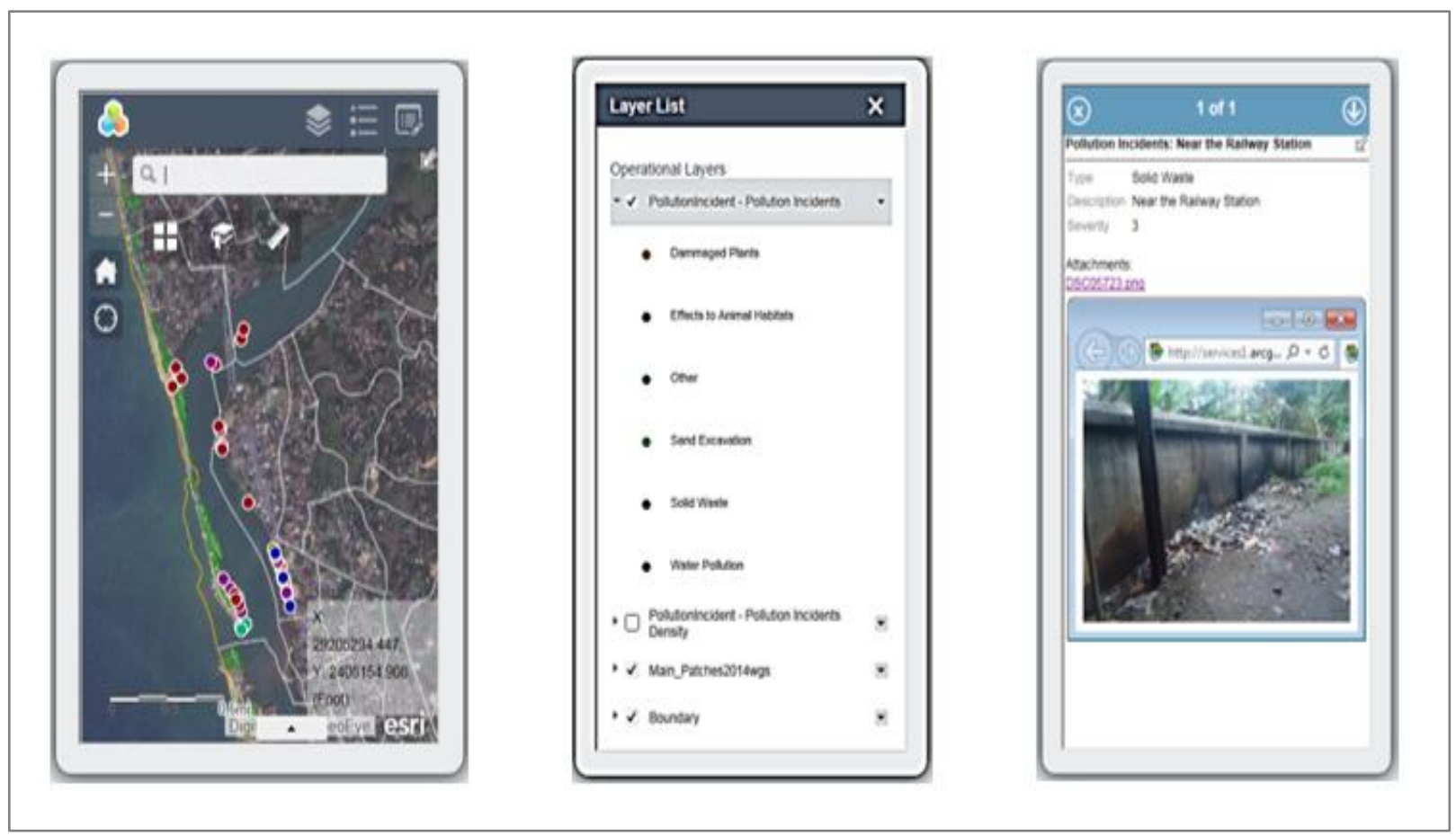

Figure 4: The interface of the data collection app, list of layers and attachments.

Using the collected incident locations, a point density analysis was done with considering the severity level. Using ArcGIS software, the Kernel Density tool was used and as the population (weighted) field, the severity field was given. The algorithm used to determine the default search radius, also known as the bandwidth, is as follows: Calculate the mean centre of the input points. If a population field other than none was selected, this, and all the following calculations, will be weighed by the values in that field. Calculate the distance from the (weighted) mean centre for all points. Calculate the (weighted) median of these distances, Dm. Calculate the (weighted) Standard Distance, SD. 
Apply the formula in equation 1 to calculate the bandwidth:

Search Raduis $=0.9 \times \min \left(S D, \sqrt{\frac{1}{\ln (2)}} * D m\right) \times n^{-0.2}$

Where: $\quad S D=$ Standard distance

$D_{m}=$ Median distance

$n=$ Number of points if no population field is used, or if a population field is supplied, $n$ is the sum of the population field values.

The min part of the equation means that whichever of the two options that results in a smaller value will be used. This approach to calculating a default radius generally avoids the "ring around the points" phenomenon that often occurred with sparse datasets (ArcGIS Resource Center, 2014).

\section{Results}

As the results, pollution incidents were identified throughout the study area and there was a significant effect to the minor environmental elements. Most of the cases are distributed nearby locations to the river and solid waste deposits were concentrated around the lagoon area. In fact these waste materials may be having different levels of effects on to this environment. Chemical effect cannot be measurably identified from the field but visual pollution as well as the level of stink has an indirect indication of the live measurements by human sensors. These live observations were reported to the dashboard for further interpretation of the incidents. According to the reported incidents the data was categorized and important information was derived. From the field observations, 44 locations were uploaded to the system and highest incident were related to the solid waste depositions (Table 1).

Table 1: Reported pollution incidents and descriptive statistics.

\begin{tabular}{lcc}
\hline Pollution Type & No of Incidents & Percentage \\
\hline Damaged plants & 12.00 & 27 \\
Effects to animal habitats & 3.00 & 7 \\
Other & 1.00 & 2 \\
Sand excavation & 4.00 & 9 \\
Solid waste & 16.00 & 36 \\
Water pollution & 8.00 & 18 \\
Sum & 44.00 & 100 \\
Average & 7.33 & 17 \\
Max & 16.00 & 36 \\
Min & 1.00 & 2 \\
\hline
\end{tabular}

Further reviewing the data, Figure 4 indicates the comparison of all the incidents which have been reported in the study area during the observed period. Solid waste depositions, damaging costal vegetation and water related pollution incidents cover more than $80 \%$ of the incidents. 


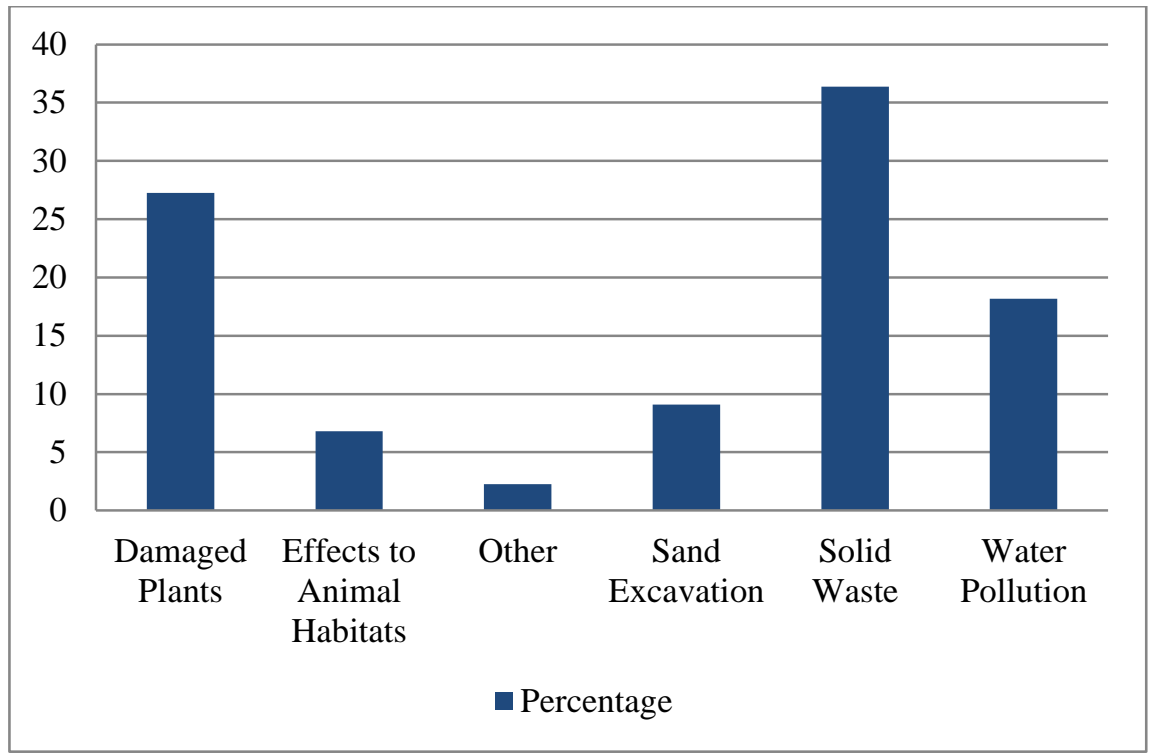

Figure 5: Comparison of the incidents.

The Kernel Density analysis has given important information regarding the overall pollution effect. Especially, several areas around the lagoon were reported clustered incidents. As the severity was considered and weighed, the south eastern part of the study area reflected a hotspot for pollution effects. Figure 6 indicate the density map for reported pollution incidents.

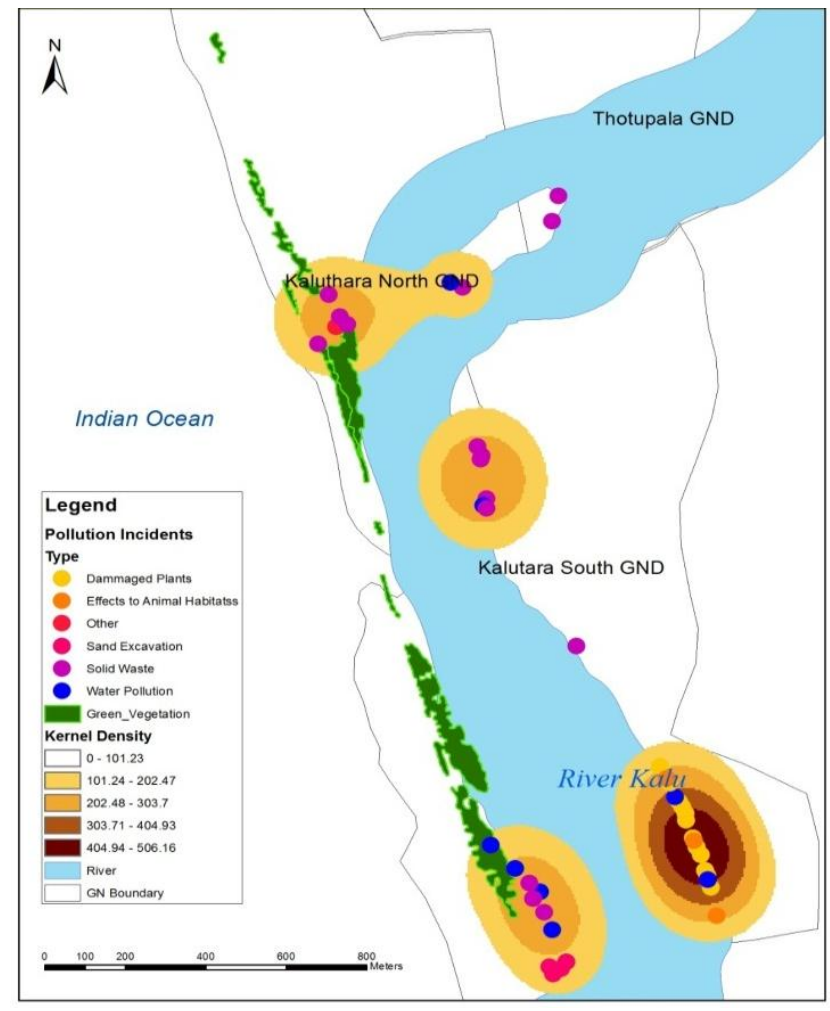

Figure 6: The density map for reported pollution incidents. 


\section{Discussion}

When analysing the reported incidents a fact was found that the average level of the incidents was 7.33 during the observed period. However, for the solid waste deposits are four time larger than the average value and clearly indicates the effect from the waste (Table 2). There was more concentration around the lagoon area and it can be interpreted as an impact forms the river and pollutants which were fallen from the distance areas and deposited at the lagoon. But these wastes may be coming from the nearby areas or from the visitors to the site.

Table 2: The deviation of the reported pollution incidents.

\begin{tabular}{lccc}
\hline Pollution Type & Percentage & Median & Deviation \\
\hline Damaged Plants & 27 & 7.33 & 19.67 \\
Effects to Animal Habitats & 7 & 7.33 & -0.33 \\
Other & 2 & 7.33 & -5.33 \\
Sand Excavation & 9 & 7.33 & 1.67 \\
Solid Waste & 36 & 7.33 & 28.67 \\
Water Pollution & 18 & 7.33 & 10.67 \\
\hline
\end{tabular}

As the initial level of the observations the incidents are only made for a 3 day period but this is currently developing into a periodic data collection for more advanced time series analysis. There was a hotspot identified in the south eastern part of the study area. It indicates the human interactions and nearby settlements have more impact on these incidents. However, there is another hotspot at the river mouth and most of the cases due to the depositions of the river. But there were a solid waste deposition which indirectly indicates the pollutants which have been dropped into the river. Figure 7 was taken during the field survey and it shows the artificial plastic water bottles collected at the river mouth area.

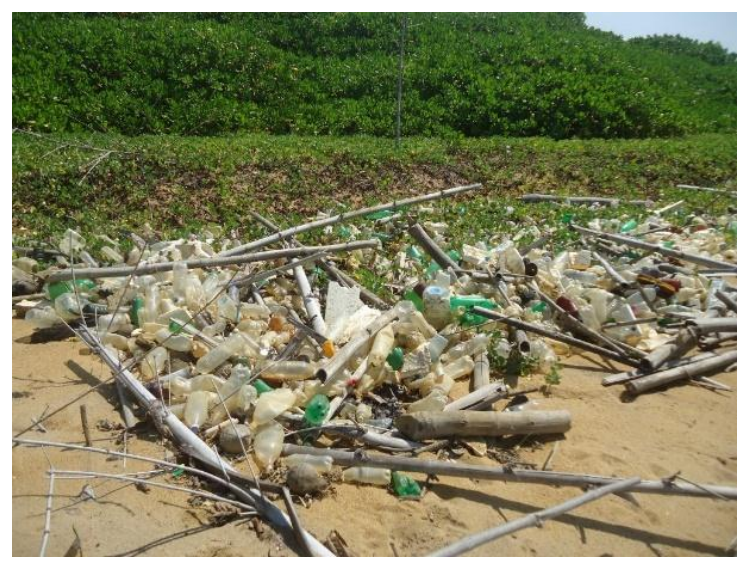

Figure 7: Solid waste depositions at the river mouth.

When reviewing the technical infrastructure, the cloud platform which is used to facilitate the data collection, has a significant level of efficiency, but when the signal strength become weak in the mobile devices, the app's performance was getting low. Especially the base maps (the background maps) were delayed to draw. The other disadvantage in this type of system is the cost of the services based on the amount of data. As a user has to pay for the services and facilities in the cloud, the large amount of data will increase the cost. This research has a mechanism of incident reporting using a cloud based IT facilities and a way of monitoring the incidents using geographical perspective. This 
type of approach has an impact for many organisations who are involved in environmental protection. This can be used as a guideline for testing practical applications for those organisations. There is an opportunity of integrating participatory GIS as well as community engagement. The importance of the study is not only identifying the current pollution effects, but also the development of next generation applications of GIS which engage responsible organisation's field staff, experts, decision makers, and the community.

\section{Conclusion}

The pollution monitoring is one of the important aspects for the sustainability of environment. There are many organisations who involves in these activities and this type of infrastructure will be important in many ways. In this scenario GIS based cloud infrastructure, helped to bring down the barriers of data sharing in a significant way. Therefore, the incident reporting mechanism became more convenient during the field observations. The dashboard represents an efficient way of identifying pollution as well as a decision supporting procedure for preventing coastal environmental pollution. The advantages of using cloud infrastructure can be identified as reduction of hardware and software limitations and bring down the barriers of data sharing. But there are disadvantages such as amount of data uploads will gain cost for the users.

\section{References}

Amaeze, N.H., PhilominathanEgonmwan, R.I., Jolaoso, A.F. and Otitoloju, A.A. 2012. Coastal Environmental Pollution and Fish Species Diversity in Lagos Lagoon, Nigeria. http://webcache.googleusercontent.com/search?q=cache:k9g_BG_ISYsJ:www.academicpub. [Accessed 20 Nov 2014]

Alesheikh, A.A., Helali, H. and Behroz, H.A. Web GIS: Technologies and Its Applications Dept. of Geodesy and Geomatics Eng., K.N.Toosi University of Technology http://www.isprs.org/proceedings/XXXIV/part4/pdfpapers/422.pdf [Accessed 20 Nov 2014]

ArcGIS Resource Center. 2015. http://resources.arcgis.com/en/help/main/ 10.2/index.html\# Howkernel Densityworks [Accessed 22 Oct 2014]

Atheull, A.N., Din, N., Longonje, S.N., Koedam, N. and Guebas, F.G. 2009. Commercial activities and subsistence utilization of mangrove forests around the Wouri estuary and the Douala-Edea reserve.http://www.ulb.ac.be/sciences/biocomplexity [Accessed 29 Nov 2014]

Bhat, M.A., Ahmad, B. and Shah, R.M. 2011. Cloud Computing: A solution to Geographical Information Systems (GIS).http://www.enggjournals.com/ijcse/doc/IJCSE11-03-02006.pdf. [Accessed 23 Nov 2014]

Choi, J.Y., Engel, B.A. and Farnsworth, R.L. Web-based GIS and spatial decision support system for watershed management.

Cloud Computing. 2014. http://www.cloudcomputingdefined.com [Accessed 10 Oct 2014]

Esri Knowledge Base. 2015. http://support.esri.com [Accessed 16 Oct 2014]

FAO. 1998. Status of Urban Trees and Forests in the region - Regional overview of urban forest resources. http://www.fao.org/docrep/003/x1577e/X1577E06.htm\#TopOfPage/ [Accessed 29 Nov 2014]

Fedra, K. andFeoli, E. 1998. GIS technology and spatial analysis in coastal zone management, Published in: EEZ Technology. http://www.ess.co.at/SMART/PUBLIC/coastal.pdf. [Accessed 25 Nov 2014]

Kelly, N.M. and Tuxen, K. 2002.WebGIS for Monitoring "Sudden Oak Death' in coastal California. http://kellylab.berkeley.edu/storage/papers/2002.Kelly.Tuxen.CEUS.pdf. [Accessed 10 Dec 2014] 
Keenan, P.B.1997. Spatial decision support systems: extending the technology to a broader user community, University College Dublin, Department of Management Information Systems, Belfield, Dublin 4, Ireland. http://mis.ucd.ie/Members/pkeenan/extendsdss.pdf. [Accessed 10 March 2014]

Kouyoumjian, V. 2010.GIS in the Cloud. Publishing Esri. http://www.esri.com/library/ebooks/gis-inthe-cloud.pdf. [Accessed 11 Dec 2014]

Kulawiak, M., Prospathopoulos, A., Perivoliotis, L.,łubaa, M., Kioroglou, S. and Stepnowski, A. 2010. Interactive visualization of marine pollution monitoring and forecasting data via a Web based GIS. http://www.sciencedirect.com/science/article/pii/S0098300410001603. [Accessed 28 Nov 2014]

Maisonneuve, M., Stevens, M. and Ochab, B. 2010.Participatory noise pollution monitoring using mobile phones.ftp://prog.vub.ac.be/tech_report/2010/vub-tr-soft-10-14.pdf. [Accessed 14 Nov 2014]

Mann, K. 2011. Fast, reliable support for disaster response, Publishing EsriArcUser. http://www.esri.com/news/arcuser/0311/files/cloudgis.pdf. [Accessed 11 Dec 2014]

Rajasekar, S., Philominathan, P. andChinnathambi, V. 2013.Research Methodology. http://arxiv.org/pdf/physics/0601009.pdf. [Accessed 12 Dec 2014]

Silva, E.I.L., Katupotha, J., Amarasighe, O., Manthrithilake, H. and Ariyaratna, R. 2013. Lagoons of Sri Lanka, International Water Management Institute, Sri Lanka.

William, A. 2009.The Role of Statistics in Research.Heldref Publications. http://faculty.tru.ca/mreudink/Methods_of_Biological_Inquiry/Entries/2010/7/12_Week_4_Re dings_files/Asher\%201993.pdf. [Accessed 26 November 2014]

Yilma, A.D. 2004. Use of Geospatial Technologies for Environmental Protection in Ethiopia. Published by Environmental Protection Authority. http://www.unoosa.org/pdf/sap/2004/sudan/presentations/07-02_2.pdf. [Accessed 20 December 2014] 